Nicholas P. Mason

Andrew D. Yeoman

\section{Comments on 0'Brien et al.: Prevalence and outcome of cirrhosis patients admitted to UK intensive care: a comparison against dialysis- dependent chronic renal failure patients}

Accepted: 29 July 2012

Published online: 18 September 2012

(C) Copyright jointly held by Springer and ESICM 2012

An authors' reply to this comment is available at doi:10.1007/s00134-012-2704-z.

Dear Editor,

We read with interest the article by O'Brien et al. [1] on the prevalence and outcome of patients with cirrhosis admitted to British ICUs. While the authors raise important points regarding the high mortality of decompensated cirrhosis and the increasing burden placed on critical care services by such patients, we feel their interpretation should not go unchallenged as there are several major limitations to the analysis that mitigate their bold and nihilistic conclusions.

Firstly, as the authors themselves partly acknowledge, chronic renal failure is clearly not the same as hepatic failure. The outcome for patients with dialysis dependent endstage renal disease (ESRD) admitted to the ICU is surprisingly good, is better than that of patients admitted with acute kidney injury and has frequently been reported to be little different from that of the general ICU population [2]. In addition, a treatment does exist that directly addresses the underlying organ failure in ESRD, but no such equivalent is available for hepatic failure. We do not believe therefore that the authors' argument that the two conditions are comparable for the sake of their analysis can be in anyway justified.

The second shortcoming of the paper relates to its use of the Intensive Care National Audit \& Research Centre (ICNARC) database. This brings with it several major problems in terms of data availability. The ICNARC and Acute Physiology and Chronic Health Evaluation II (APACHE II) models do not collect parameters that quantify either the presence or severity of liver disease. This limits the utility of these models to predict outcome in patients with liver disease, likely explaining why the ICNARC and APACHE II scores were higher for dialysis-dependent ESRD patients compared with patients with cirrhosis and significantly under-predicting mortality for this latter group. In contrast, evidence does exist that the Sequential Organ Failure Assessment (SOFA) score (which includes bilirubin as one of its parameters) performs better than APACHE II score in predicting outcome in patients with cirrhosis admitted to the ICU [3].

A further weakness of the article is the inability to identify the specific reason for ICU admission. For example, variceal bleeding is the commonest reason for ICU admission in many series [3], and ICU mortality has been demonstrated to have fallen threefold between 1980 and 2000 [4]. However, there is no way to interpret the authors' data in the absence of specific admission data.

It is undeniable that mortality in patients with cirrhosis who develop multiple organ failure is high and that the development of sepsis is a grave prognostic sign, but we would challenge the assertion that we should seek to identify earlier those patients with a poor prognosis so we can exclude them from critical care. Rather, our focus should be to more rapidly identify sepsis and organ dysfunction and admit such patients earlier to critical care units to prevent further deterioration in organ function with its associated increase in mortality risk. Such an approach, which is in direct contrast to the prognostic pessimism proposed by the authors, may then begin to deliver the improvement in outcome seen in severe sepsis in recent years [5] and produce further increases in survival in patients with cirrhosis above the $5 \%$ reduction in mortality over time that the authors report.

\section{References}

1. O'Brien AJ, Welch CA, Singer M, Harrison DA (2012) Prevalence and outcome of cirrhosis patients admitted to UK intensive care: a comparison against dialysis-dependent chronic renal failure patients. Intensive Care Med 38:991-1000. doi: 10.1007/s00134-012-2523-2

2. Thompson S, Pannu N (2012) Dialysis patients and critical illness. Am J Kidney Dis 59:145-151

3. Cholongitas E, Senzolo M, Patch D, Shaw S, Hui C, Burroughs AK (2006) Review article: scoring systems for assessing prognosis in critically ill adult cirrhotics. Aliment Pharmacol Ther 24:453-464

4. Carbonell N, Pauwels A, Serfaty L, Fourdan O, Levy VG, Poupon R (2004) Improved survival after variceal bleeding in patients with cirrhosis over the past two decades. Hepatology 40:652-659

5. Levy MM, Dellinger RP, Townsend SR, Linde-Zwirble WT, Marshall JC, Bion J, Schorr C, Artigas A, Ramsay G, Beale R, Parker MM, Gerlach H, Reinhart K, Silva E, Harvey M, Regan S, Angus DC (2010) The Surviving Sepsis Campaign: results of an international guidelinebased performance improvement program targeting severe sepsis. Intensive Care Med 36:222-231

N. P. Mason $(\bowtie) \cdot$ A. D. Yeoman Royal Gwent Hospital, Newport, UK e-mail: nick.mason@wales.nhs.uk

A. D. Yeoman

e-mail: andrew.yeoman@wales.nhs.uk 